\title{
PHARMACEUTICAL INDUSTRY COMPLIANCE WITH INDUSTRY GUIDING PRINCIPLES FOR DIRECT-TO-CONSUMER ADVERTISING
}

\author{
Denis G. Arnold, University of North Carolina at Charlotte, USA \\ James L. Oakley, University of North Carolina at Charlotte, USA
}

\begin{abstract}
Since 1997 the U.S. Food and Drug Administration has permitted direct-to-consumer prescription pharmaceutical advertising via television commercials. The pharmaceutical industry has argued that direct-to-consumer advertising is an effective means to educate consumers about diseases and appropriate treatments. In contrast, direct-to-consumer television advertising has been criticized for the level of information provided and for undermining physician patient relationships.

In response to such criticism, the Pharmaceutical Research and Manufacturers of America (PhRMA) has utilized a set of industry guidelines for self-regulating these advertising messages directed to consumers since 2006. Since companies pledge to adhere to the PhRMA Guiding Principles, and since the Guiding Principles may be regarded as a substitute for new federal regulation of direct-to-consumer advertising, it is important to know whether or not individual pharmaceutical company practices are actually in compliance with the Guiding Principles.
\end{abstract}

This study assesses compliance with the PhRMA guidelines for pharmaceuticals intended for the treatment of erectile dysfunction. In order to assess company compliance with the original and revised Guiding Principles we selected principles for which publicly available information suitable for determining compliance could be acquired and undertook multidimensional data collection and analysis. Utilizing data from TNS Media and AC Nielsen, in addition to content analysis, readability analysis, and primary viewer surveys, compliance with eleven of the fifteen PhRMA guidelines is assessed over four years, from 2006-2009.

Our data illustrates that while total pharmaceutical industry spending on direct-to-consumer media has declined slightly since 2007, annual spending on direct-to-consumer erectile dysfunction media during the period in which the PhRMA guidelines have been in effect has increased to $\$ 313.4$ million in 2009 from $\$ 200.3$ million in 2006. Over the four-year period of our study, nearly 100,000 television advertisements aired for erectile dysfunction drugs, and our data indicates that viewers regard direct-to-consumer advertising for erectile dysfunction drugs as manipulative and coaxing rather than educational and instructive.

The findings from our study suggest that instead of facilitating a balancing of interests, the self-regulation efforts of the pharmaceutical industry through PhRMA and its associated guidelines are serving the interests of pharmaceutical companies at the expense of public health education and welfare.

References available upon request 